\title{
A clinical study of Gilles de la Tourette syndrome in the United Kingdom
}

\author{
AJ LEES, MARY ROBERTSON, ${ }^{*}$ MR TRIMBLE, NMF MURRAY \\ From The National Hospital for Nervous Diseases, Queen Square, London, UK
}

SUMMARY The clinical features of 53 British-born patients with Gilles de la Tourette syndrome are described. The mean age at onset of body tics was seven years and for vocalisations 11 years. Coprolalia was present in $39 \%$, copropraxia in $21 \%$, echolalia in $46 \%$ and echopraxia in $21 \%$. Complicated antics and mannerisms were also common, often involving the compulsive touching of objects or self-injurious behaviour. Forty-six per cent of cases had a family history of tics in a single close relative and in two individuals a further member of the family had Gilles de la Tourette syndrome. Focal dystonia was present in four patients who had never received neuroleptics drugs and chorea was seen in two other untreated patients. In three patients acoustic startle consistently induced brief eye blink followed by a whole body jerk or jump. Rapid repetitive movements of the hands increased the frequency and severity of tics in 13 patients, but the performance of mental arithmetic under time pressure had a much more unpredictable effect. Electroencephalographic abnormalities occurred in eight (13\%) but no definite CT brain scan abnormalities were detected. The incidence of left handedness did not differ from that in the general population and no evidence to suggest organic impairment was found on neuropsychological testing. This study provides no support for the notion that Gilles de la Tourette syndrome is a degenerative disorder of the central nervous system but provides some evidence for heterogeneity.

Tics are abrupt variable, usually repetitive coordinated muscular jerks which are relatively easy to imitate and can be voluntarily suppressed for considerable periods of time. Their pathophysiology remains obscure but they have in the past generally been considered to be environmentally determined-as Charcot put it "a psychical disorder in a physical guise". However, recent neurophysiological studies suggest that tics are not generated through the motor pathways used for normal self-paced voluntary movement ${ }^{1}$ and there has been a recent swing towards considering this phenomenon to have an underlying neurogenic cause. $^{2}$

Tic disorders range in severity from the single acute transient tic, which affects up to $10 \%$ of children, to the uncommon and sometimes socially

*The Maudsley Hospital, De Crespigny Park, Denmark Hill, SE5.

Address for reprint requests: Dr AJ Lees, the National Hospital for Nervous Diseases, Queen Sq, London WC1N 3BG, UK.

Received 29 June 1983. Accepted 2 August 1983 disabling Gilles de la Tourette syndrome. In the absence of any neurobiological distinctions between these different phenomena, they should be considered as a clinical continuum. ${ }^{3}$

The first clear medical description of the condition is to be found in the writings of Jean-Marc Itard who reported the case of the Marquise de Dampierre who was afflicted with convulsive movements of the hands and arms at the age of 7 years and at puberty developed strange screams and incomprehensible cries. Following her marriage, her bizarre contortions, vocalisations and grimaces were compounded by the utterance of strings of obscenities which belied her distinguished deportment and manners. As a consequence she was forced to live as a recluse, continuing to curse until her death at the age of $85 .{ }^{4}$ On his return to the Salpetrière Gilles de la Tourette, Charcot's chef de clinique, was delegated the task of reclassifying "the chaos of the choreas" and in 1885 in a two part paper he clearly delineated the disorder which has earned him eponymous fame. ${ }^{5} \mathrm{He}$ particularly emphasised the triad of multiple tics, coprolalia and echolalia, but in recent 
years the diagnostic criteria have become less stringent. Onset in childhood or adolescence, generalised multiple tics together with inapposite vocalisations are the featureston which the disorder is now diagnosed. Echo phenomena, coprolalia and copropraxia, and obsessional-convulsive traits are considered as additional confirmatory features but not diagnostic prerequisites.

The first reported cases of Gilles de la Tourette's syndrome in the United Kingdom may possibly have been Mary Hall of Gadsden who was reported in 1663 by William Drage. ${ }^{6}$ A convincing case has also been made that the 18th century English literary figure Samuel Johnson suffered from the disorder.? Hughlings Jackson reported a patient with the disorder in the London Hospital Gazette, his attention probably having been drawn to the condition by Gilles de la Tourette himself who had visited London some time earlier. ${ }^{8}$ Kinnier Wilson described a further case in his writings on tics ${ }^{9}$ and in 1935 Creak and Guttman reported six cases from the Maudsley Hospital which were considered to be post-infectious in aetiology. ${ }^{10}$ Fernando described a further four cases three of whom were treated as inpatients in a psychiatric hospital and reviewed seven other reported British cases. " Since then a handful of further case reports have appeared in the literature and Abuzzahab has a total of 53 (British) cases on his international registry, but no clinical details are given. ${ }^{12}$ The prevailing view therefore has remained that the disorder is a rarity in the UK, and few physicians can recall ever seeing a case. In contrast large series of cases have been reported from the USA ${ }^{13}$ and Japan ${ }^{14}$ and representative smaller series have also been published from West Germany ${ }^{15}$ and Hong Kong. ${ }^{16}$ In the present paper we report the clinical features of 53 British patients with Gilles de la Tourette's syndrome and examine the possibility that the disorder might have an underlying organic basis.

\section{Patients and methods}

Fifty-three patients with Gilles de la Tourette syndrome were studied between 1980 and 1982 . All were Britishborn North European caucasians except for seven of Ashkenazim Jewish stock. Most patients were referred via the United Kingdom Gilles de la Tourette Association after permission had been obtained from the general practitioners involved. A much smaller number of patients were referred directly from other hospital specialists throughout the UK.

There were 40 males (mean age 23 years) (range 7-64 years) and 13 females (mean age 27 years) (range 9-69 years); 14 of the males and four of the females were under 18 years. The disorder was judged to be severe in seven cases, marked in 11 cases, moderate in 18 cases and mild in
17 cases. Thirteen of the patients had received neuroleptics and virtually all the adult cases had received benzodiazepines, tricyclic antidepressants or monoamine oxidase inhibitors. Four of the patients had also abused psycho-motor stimulants, marijuana or LSD-25.

A detailed history was taken, corroborated in most cases by independent interviews with close relatives. All previous medical documentation was scrutinised and further clinical information was obtained by asking the patient to fill in a questionnaire. Handedness was assessed using the Annett handedness inventory' ${ }^{17}$ and a full neurological examination was performed paying particular attention to the possibility of minor motor asymmetries being present. WAIS or WISC neuro-psychological testing ${ }^{18} 19$ was administered by the Department of Clinical Neuropsychology at the National Hospital. Computed tomography of the brain and electroencephalograms were reported routinely by radiological and neurophysiological colleagues and then independently assessed by one of us. Laboratory investigations included copper and calcium studies and peripheral blood films to look for the presence of acanthocytes.

\section{Results}

Only 15 of the patients had received the correct diagnosis before referral. The commonest misdiagnoses were St. Vitus dance, epilepsy, or some form of psychiatric illness. The mean age at onset of symptoms was seven years (SD $2 \cdot 8$, range $7-16$ years) and a list of the presenting tics is shown in table 1. A rapid, usually unilateral eye blink or a repetitive head and neck jerk were commonest; vocalisations were the presenting feature in $15 \%$ of cases. In some patients a cluster of different tics appeared virtually simultaneously, whereas in others many months elapsed before new tics either replaced or were superimposed upon pre-existing ones. Many of the patients had a virtually limitless repertoire of abnormal movements which had waxed and waned throughout childhood and adolescence.

Ninety-four per cent of the patients had experienced facial tics at some stage including eyeblinks, eyebrow raising, frowning, rolling of the eyes, grimacing, staring, nose wrinkling, mouth opening, lip pursing, jaw protrusions, pouting,

Table 1 Presenting tic

\begin{tabular}{lr}
\hline Eye blink & 19 \\
Head toss & 10 \\
Vocalisation & 8 \\
Shoulder shrug & 3 \\
Tongue protrusion & 2 \\
Grimace & 2 \\
Sniff & 2 \\
Mouth opening & 1 \\
Leg jerk & 4 \\
Dont know & \\
\hline
\end{tabular}


tongue flicking and snarling. Movements of the head and neck were only slightly less common, occurring in $89 \%$ of patients and comprising head tossing, head nodding, head swivelling or jerking and shoulder shrugs. Only $51 \%$ of patients had tics of the arms which usually consisted either of whole arm jerks, rapid finger movements or flexion extension movements of the elbow. Movements of the trunk including body rocks, rapid pelvic thrusts, buttock tightening, chest expansion and shudders occurred in $41 \%$ of patients. Tics of the legs were least common of all affecting only $40 \%$ of patients. Rapid kicks, toe curling, striking one leg rapidly with the other and hip abductions were seen.

The mean age at onset of vocalisations was 11 years (SD 6.8, range 4-33 years) and the commonest varieties are shown in table 2. Atavistic menagerie noises such as barks and grunts, colloquial emotional exclamations and repetitive throat clearing, sniffing, belching and hiccoughing were the usual sounds.

Tics and vocalisations were invariably aggravated by anxiety, stress or excitement, but other occasional provoking factors included fatigue, boredom, talking to strangers, watching television, derogatory personal comments addressed to the patient or depression. Two of the female patients reported their tics to be worse pre-menstrually. Sleep, relaxation or concentration on an enjoyable task usually led to their temporary disappearance and individual patients found music, driving a motor vehicle, dancing, agreeable company, alcohol and love-making efficacious. Two patients remitted completely for more than a year and a further eight for several months. Most, however, had never been totally free of tics for more than a day or two since their inception.

A history of tics was present in an immediate family member in 24 cases and in six patients more than one close relative had tics. One boy had a grandfather who had suffered with Gilles de la

Table 2 Cumulative past and present vocalisations

\begin{tabular}{lrll}
\hline Grunt & 16 & Whoop & 2 \\
Throat-clearing & 15 & Hiss & 2 \\
Bark & 9 & Growl & 1 \\
Snort & 7 & Wa Wa & 1 \\
Ugh & 6 & Sucking Noise & 1 \\
Ah & 6 & Sh, Sh, Sh & 1 \\
Gulp & 5 & Pant & 1 \\
Hiccough & 5 & Wail & 1 \\
Click & 3 & Eh & 1 \\
Hum & 3 & Quack & 1 \\
Squeak & 3 & Gasp & 1 \\
Shriek & 3 & Cluck & 1 \\
Burp & 3 & Yelp & 1 \\
Hoot & 2 & Yahoo & 1 \\
Ooh & 2 & T, T, T, T & 1 \\
Moon & 2 & Glug & 1 \\
\hline
\end{tabular}

Tourette's syndrome and one of the female patients had a similarly affected son. Possible birth complications were reported in 13 patients (induced labour 3 , umbilical cord round the neck 3 , neonatal jaundice 2 , caesarian section 2 , forceps delivery 2 , prolonged labour 1 , prematurity 1 and twin sibling dying at birth 1).

All the adult patients and many of the children also exhibited an array of complicated antics and mannerisms which added to their bizarre appearance. Compulsive touching $(61 \%)$ and striking $(36 \%)$ were most frequent, popular objects to touch included hot things such as fires, irons, hot plates and lighted cigarettes, door handles, railings and floors, or fabrics with an erotic texture such as fur, velvet, satin and silk. Compulsive touching of breasts, bottoms and hair were also frequent and individual patients touched noses, heads, lips, rounded stones and sharpened knives. In contrast striking was usually directed towards the patients own body and was commoner in females. Punching or hitting the head, head banging, self-inflicted lacerations or bites and walking deliberately into things were reported, but lip-chewing or finger mutilation as occurs in Lesch-Nyhan syndrome were not seen. One patient gouged his eye badly by constant picking and scratching and another detached his retina as a consequence of repeated blows to the head.

Coprolalia was present in 20 patients, the mean age of onset being 14.5 years (SD 6.7, range 7-31 years), and mental coprolalia was reported in a further four patients. Four letter words with sexual connotations were particularly frequent and in descending frequency included fuck, cunt, bastard, piss, sod, cock, and shit. Attempts to down-grade the impact of the swear word by the use of euphemisms or thinly disguised neologisms were common. These obscenities were frequently uttered in private in the patients home or in public lavatories and when they occurred in the course of conversation would tend to break through during pauses between sentences. The curse was usually uttered in a loud sharp tone which contrasted with the otherwise normal prosody.

Copropraxia was reported in $11(21 \%)$ of the patients, nine of whom had coprolalia. The commonest gesture was the palm-backed $\mathrm{V}$ sign but several individuals also used the forearm jerk with the fist clenched and two patients the clenched fist with an extended index finger. Four male patients simulated masturbation with rhythmical hand movements and pelvic thrusting. As with coprolalia simultaneous attempts to disguise the distasteful actions were attempted. Other non-obscene gestures were also common including the thumbs up and victory $\mathrm{V}$ sign. 
Echolalia had occurred at some time in 23 patients and echopraxia in 11. As with copro phenomena the mean age of onset was in early adolescence at 13 years (SD 5.6, range 10-23). Some patients repeated whole sentences whereas others restricted themselves to a word. Many repeated the noises of animals or celebrities voices heard on television. Some patients also imitated the accent and one repeated things in a ventriloquist fashion. A further patient recorded speech on a tape recorder and then played it back immediately in front of the recorded speaker. In addition to the imitation of other peoples body language and mannerisms, six patients also exhibited motor perseveration with the repetition of a spontaneously occurring movement or gesture. Nine patients had a history of stammering and two frequently repeated the last word of short sentences two or three times.

\section{NEUROLOGICAL FINDINGS}

Forty-seven of the patients were right handed $(37$ complete right handers, 10 predominant right handers) two were ambidextrous and four were left handed. Rapid repetitive movements of the hands led to an increase in the severity of tics in other parts of the body in 13 patients and motor impersistence occurred in another four. In one patient rapid repetitive pronation-supination movement of the wrist induced cramp-like spasms of the hands preventing further movement; repetitive foot tapping in the same individual led to involuntary flexion/ extension toe movements. The performance of mental arithmetic under time pressure increased tic severity in six and improved it in a further seven. Chorea of the limbs and head was present in four patients, but one of these had received neuroleptics and a further case had abused amphetamines for long periods. One patient had dystonic arching of the back and two had tonic torticollis, and a further case spasmodic dysphonia. None of these had received neuroleptics. In response to startle such as a loud unexpected noise three patients consistently developed eyeblinks and general body jerks or jumps which closely resembled their tics. Mild unilateral dysdiadokochinesia was present in three patients and two of the patients on neuroleptics had some extrapyramidal rigidity. Three patients had intermittent postural abnormalities with drooping of the head or neck or mild intermittent flexion of the trunk.

\section{NEUROPSYCHOLOGICAL ABNORMALITIES}

The mean WAIS and WISC verbal IQ for the patients was $100 \cdot 2$ (SD 13.2) and performance IQ 99.8 (SD 13.4). Three of the patients had a verbal IQ of 15 points or more greater than performance
IQ and two patients a performance IQ greater than the respective verbal IQ by a similar margin. Ten of the patients were distractable with poor attention spans, four of these also had selective mild visual memory defects and three specific writing and reading deficits.

ELECTROENCEPHALOGRAPHIC ABNORMALITIES The most striking feature of the EEGs was the frequent occurrence of electromyographic activity corresponding to tics (see fig). This ranged from single spikes to prolonged bursts of muscle activity recorded over a large area of the scalp. EEG abnormalities were present in eight patients. In one individual with severe Gilles de la Tourette syndrome who had been off neuroleptic medication for seven days bursts of spike and wave activity occurred in the resting record, on one occasion in association with a tic and on photic stimulation. Episodic focal abnormalities with sharp theta waves in the temporal regions occurred in a further two patients and in five subjects two of whom were on neuroleptics there was a mild diffuse excess of theta activity and in one of whom paroxysms of six cycles/ second activity also occurred.

\section{CT BRAIN SCANS}

With the exception of one patient in which a slight abnormality at the foramen of Munro was queried no abnormalities were detected.

\section{BIOCHEMICAL ABNORMALITIES}

Marginally low serum copper levels with normal serum caeroplasmins were found in five patients and a further two patients had elevated serum copper levels with normal caeroplasmins. There were no abnormalities of serum calcium and no patients were found to have acanthocytosis.

\section{Discussion}

Although there has been a remarkable degree of cross cultural uniformity in the series of patients with Gilles de la Tourette syndrome reported from different countries, minor differences have emerged. ${ }^{12}$ The most marked of these has been the extremely low incidence of coprolalia in Japanese patients, only $4 \%$ of 97 patients in one study manifesting this abnormality. ${ }^{14}$ The present study failed to reveal any significant differences in the clinical features of the disorder when compared with the previous American studies. ${ }^{132021}$

Shapiro and colleagues ${ }^{13}$ are firm advocates of an organic aetiology for Gilles de la Tourette's syndrome, basing their thesis on circumstantial evidence derived principally from their own extensive 

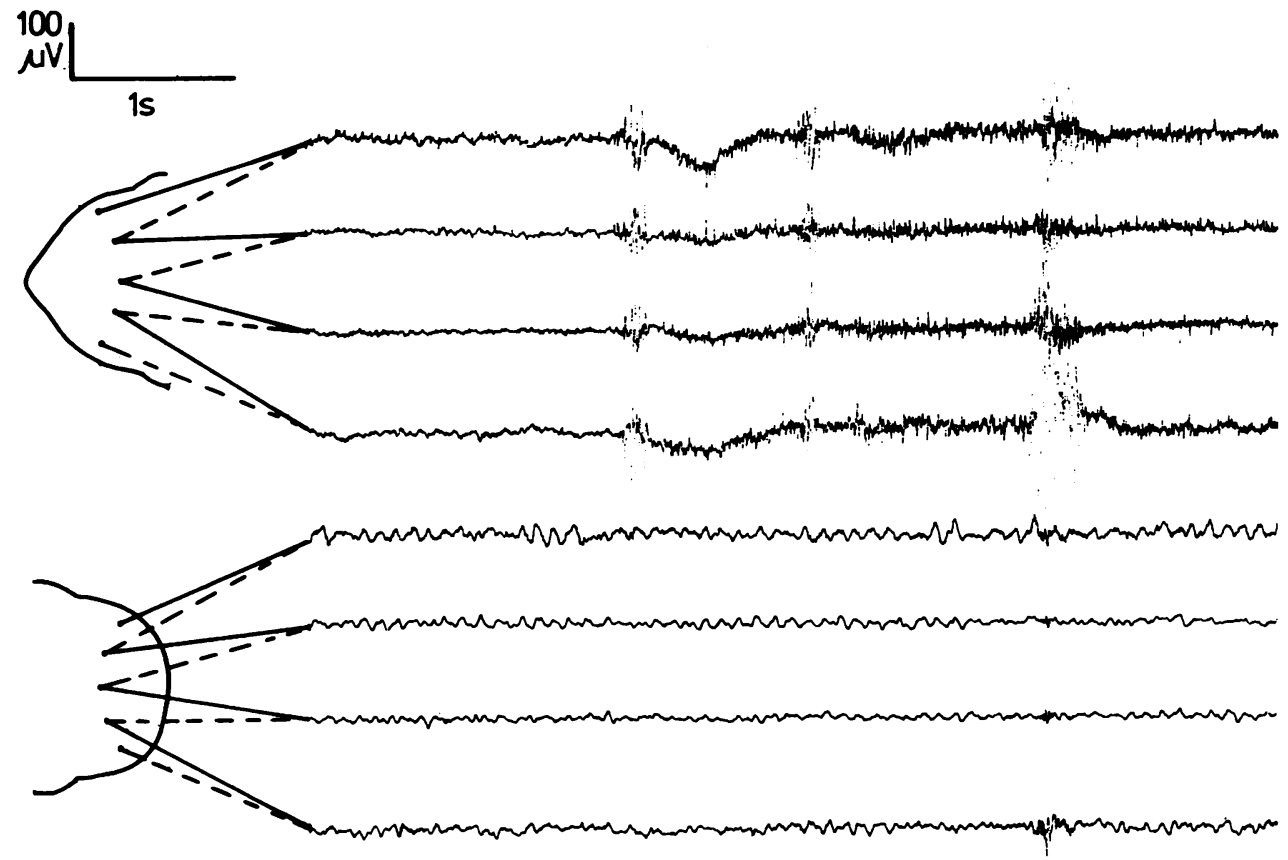

Figure Unilateral muscle activity corresponding to tics seen on the electroencephalogram

clinical studies. Of their 114 personally studied patients $57.6 \%$ had minor motor asymmetries on neurological examination of a type similar to those found in children with minimal brain dysfunction. Twenty per cent of their patients were left handed or ambidextrous, $68 \%$ had evidence of organic impairment on WAIS or WISC neuropsychological testing and $46.8 \%$ had electro-encephalographic abnormalities. They also cite the high male:female sex ratio, genetic factors and the stereotyped clinical picture as arguments in support of a structural organic cause. It is also known that tics and vocalisations may occasionally be acquired as a sequel to epidemic encephalitis lethargica ${ }^{22}$ or following diffuse cerebrovascular disease ${ }^{23}$ head injuries ${ }^{24}$ and carbon monoxide poisoning. ${ }^{25}$ Sacks has also seen the symptoms of Gilles de la Tourette syndrome in association with epilepsia partialis continuans, strokes and Huntington's chorea. ${ }^{26} \mathrm{~A}$ few cases of neuroleptic-induced Gilles de la Tourette syndrome have also been documented. ${ }^{27}$ However, in the only two cases of Gilles de la Tourette syndrome that have been carefully studied post mortem no distinctive histopathological abnormalities have been found. ${ }^{28}$

EEG abnormalities were seen in only eight of our patients and in two of these the excess slow wave activity may have been due to concurrent neuroleptic administration. These findings are in broad agreement with a recent study which excluded patients with evidence of associated neurological damage or those taking neuroleptics and found abnormalities on the EEG in only four of 23 patients. ${ }^{29}$ The much higher incidence in other studies $^{1330}$ may be related to different patient populations, the presence of associated brain damage and drug effects. Furthermore none of these studies reveals a consistent type of electroencephalographic abnormality which might reflect the pathophysiological basis of the movement disorder. The findings taken as a whole would be much more in keeping with some of the patients having additional heterogeneous central nervous system lesions. The frequency of muscle artefacts on many of the records can make interpretation difficult and some of the finer muscular discharges seen in our study were identical to those reported to occur in hyperactive children with Prechtls choreiform syndrome. ${ }^{31}$ The frequency of this EMG activity appears to bear a direct relationship to tic severity and may be used to quantify the effects of drugs on tic disorders. ${ }^{32}$ CT scans of the brain revealed no significant abnormalities in the present study. This contrasts to a recent report in which six of 16 patients with the syndrome were reported to have some sort of abnormality. These included mild asymmetrical dilatation of the lateral ventricles and prominent Sylvian fissures or cortical sulci. Four of 
the patients also had abnormal EEGs. Careful controlled studies are needed to evaluate the significance of these relatively minor abnormalities. ${ }^{33}$

The clinical distinction between chorea, myoclonus and tics can on occasions be extremely difficult. As a consequence, video films of the patients in whom we believed myoclonus chorea or dystonia to be occurring in association with Gilles de la Tourette syndrome were shown to other neurologists either at neurological meetings or informally. In those patients who had received neuroleptics, evaluation of these dyskinesias was difficult as it is well recognised that tardive dyskinesias and tardive dystonia may occur occasionally in Gilles de la Tourette syndrome. ${ }^{34}$ One of the patients had also been abusing amphetamines for several years which can also produce a choreiform syndrome..$^{35}$ Nevertheless the occasional association of abnormal involuntary movements believed to arise from the basal ganglia in untreated patients with Gilles de la Tourette syndrome could be construed to favour the notion held by the German School of neurology that tics emanate from sub-cortical structures. Alternatively it might be argued that within the clinical spectrum of Gilles de la Tourette syndrome reside a heterogeneous group of conditions some of which may have an underlying structural cause. It is of interest that $\mathrm{Osler}^{36}$ and subsequently Creak and Gutmann ${ }^{10}$ reported tics occurring after rheumatic fever and more recently coprolalia has been observed in a few well documented cases of Sydenham's chorea. In most instances, however, there is no difficulty in distinguishing between Sydenham's chorea and Gilles de la Tourette's syndrome, the former rarely persisting for more than one year and the movements being of a different quality.

Gilles de la Tourette in his original description compared "Maladie des Tics" to Latah, Miryachit and the Jumping Frenchmen of Maine, disorders which are now more generally considered to be culturally-determined adaptations of an underlying exaggerated startle response. These disorders do not have tics as part of their symptomatology and are characterised by the association of startle myoclonus with echolalia coprolalia or automatic obedience. Corbett ${ }^{37}$ has drawn attention to the similarity between the nature and distribution of tics and the movements comprising the physiological startle response. On the basis of studies with high-speed photography and video tape recordings he has postulated that tics may be a developmental disorder arising out of a conditioned startle reflex. Thorne ${ }^{38}$ described a syndrome of startle neurosis which he estimates to occur in about one in 2000 healthy male subjects. A recent newspaper article harvested 12 of these individuals some of whom reported throwing or dropping objects, jumping, uncontrollable vocalisations and in one instance involuntary cursing in response to surprise or startle. ${ }^{39}$ In three $(5 \%)$ of our patients startle consistently induced eyeblink tics, a generalised myoclonic body jerk or jumps. Of Shapiro's patients ${ }^{13} 1.4 \%$ were also mentioned as having a startle reaction.

The characteristic EEG finding in the hyperekplexias (a familial disorder due to a pathologically exaggerated startle reflex) is a positive sharp wave of $80-100 \mathrm{~ms}$ which is followed by one or more delta waves, each lasting a half to one second. ${ }^{40}$ It has recently been suggested that the vertex sharp wave may in fact be due to sudden eyeball retraction at the onset of the startle response. Markand and his colleagues however have also recently demonstrated that in one family with hyperekplexia, there were enhanced long loop reflexes similar to those seen in cortical myoclonus. ${ }^{41}$ Although no abnormalities of somatosensory evoked potentials have as yet been found in Gilles de la Tourette syndrome further neurophysiological investigation may prove rewarding.

The frequent occurrence of coprolalia in Gilles de la Tourette syndrome has been used to support psycho-analytical theories concerning its aetiology. It can, however, occur as a result of structural damage to the central nervous system and it is well recognised that occasionally patients with severe aphasia following a stroke may still utter obscenities. Nuwer ${ }^{42}$ has drawn attention to the preponderance of four letter obscenities relating to physical acts in Gilles de la Tourette's syndrome, and in our series religious profanities such as God, Hell and Damn frequently used in every day language were not encountered. The fact that blaspheming is considered less taboo in English than swear words relating to copulation, defaecation or micturition may be of relevance. No differences could be found between the type of curse used by the male and female patients. Coprolalia usually occurs with an unusual pitch and volume, sometimes with imprecise pronounciation of individual phonemes. The particular type of four letter profanity which occurs in Gilles de la Tourette syndrome might occur as a result of a short circuited pathway. It has been shown that these sort of obscenities are generated frequently in English and German by computer programmes which generate spoken phonemes using a Markov process. ${ }^{42}$

The present study shows that Gilles de la Tourette syndrome is by no means rare in the United Kingdom and we have had contact by means of postal questionnaires with a further 44 patients. 
Most of the adults had received wrong diagnoses during childhood, as a consequence had become disenchanted with the medical profession and were reluctant to attend even for a single hospital appointment. Several patients had spent considerable periods of time in psychiatric institutions and received therapies as varied as behavioural treatment, aversion therapy, electroshock treatment and in one instance insulin coma therapy. The recent demonstration that dopamine antagonist drugs can benefit a proportion of patients makes accurate diagnosis at an early stage important. One of our patients (DD) was the subject of an earlier report by Fernando in 1967 since which time there had been no improvement in the severity of his tics. Most of the adult patients with moderate or severe disease were severely socially disadvantaged and in spite of considerable natural ability in many cases employers had been unwilling to accept their tics and vocalisations. Nevertheless a number of patients were holding down highly responsible professional posts and others had a particular aptitude for playing musical instruments.

Our study fails to support the notion that the majority of patients with Gilles de la Tourette's Syndrome have a structural abnormality of the central nervous system. The condition, however, occurs relatively commonly in mentally retarded individuals with diffuse brain damage and a few patients with hyperekplexia, neuroacanthocytosis and drug induced dyskinesias may be clinically indistinguishable. Our own study revealed a high incidence of psychopathology in the patients and their relatives and these findings will be reported elsewhere. The present evidence would be most in keeping with the idea that Gilles de la Tourette's syndrome might occur as a consequence of a derangement of limbic and striatal function, involving central dopaminergic mechanisms.

We are most grateful to Mrs Joan Wolfe, President of the United Kingdom Gilles de la Tourette Association for her support and encouragement in this research and to our colleagues at the National Hospitals and the Maudsley Hospital who referred their patients.

\section{References}

' Obeso JA, Rothwell JC, Marsden CD. Simple tics in Gilles de la Tourette's syndrome are not prefaced by a normal premovement EEG potential. J Neurol Neurosurg Psychiatry 1981;44:735-8.

${ }^{2}$ Sweet RD, Solomon GE, Wayne H, Shapiro E, Shapiro AK. Neurological features of Gilles de la Tourette syndrome. J Neurol Neurosurg Psychiatry 1973;36:1-9.
${ }^{3}$ Corbett JA, Mathews AM, Connell PH, Shapiro DA. Tics and Gilles de la Tourette's syndrome: a follow up study and critical review. $B r \quad J$ Psychiatry 1969;115:1229-41.

${ }^{4}$ Itard JMG. Memoire sur quelques fonctions involontaires des appareils de la locomotion de la prehension et de la voix. Arch Gen Med 1925;8:385-407.

${ }^{5}$ Gilles de la Tourette G. Etude sur une affection nerveuse caracterisée par de l'incoordination motrice accompagnée d'echolalie et de coprolalie. Archives de Neurologie 1885;9:19-42, 158-200.

${ }^{6}$ Drage W. Mary Hall of Gadsden in Hertford. In: Hunter R, McAlpine I, eds. 300 years of Psychiatry. London: Oxford Univ. Press, 1663:174-7.

' Murray TJ. Dr Samuel Johnson's movement disorders. Br Med J 1979;1:1610-4.

${ }^{8}$ Hughlings Jackson J. Clinical lectures and reports to the London Hospital 1884;1:452.

${ }^{9}$ Wilson SAK. The tics and allied conditions. J Neurol Psychopathol 1927;8:93-109.

${ }^{10}$ Creak M, Guttman E. Chorea, tics and compulsive utterances. J Ment Sci 1935;81:834-9.

"Fernando SJM. Gilles de la Tourette's syndrome: a report on 4 cases and a review of published case reports. Br J Psychiatry 1967;113:607-17.

${ }^{12}$ Abuzzahab FS, Anderson FO. Gilles de la Tourette's syndrome International Registry. St. Paul: Mason Publishing Co., 1976

${ }^{13}$ Shapiro AK, Shapiro ES, Bruun RD, Sweet RD. Gilles de la Tourette syndrome. New York: Raven Press, 1978.

${ }^{14}$ Nomura Y, Segawa M. Tourette syndrome in oriental children: Clinical and pathophysiological considerations. In: Friedhoff AJ, Chase TN, eds. Gilles de la Tourette syndrome. New York: Raven Press, 1982:277-80.

15 Asam U. A follow up study of Tourette syndrome. In: Friedhoff AJ, Chase TN, eds. Gilles de La Tourette Syndrome New York: Raven Press, 1982:285-6.

${ }^{16}$ Lieh Mak F, Chung SY, Lee P, Chen S. Tourette syndrome in the Chinese: a follow up of 15 cases. In: Friedhoff AJ, Chase TN, eds. Gilles de la Tourette syndrome. New York: Raven Press, 1982:277-83.

${ }^{17}$ Annett M. A classification of hand preferences by association analysis. Br J Psychol 1970;61:303-21.

${ }^{18}$ Wechsler D. The Measurement and Appraisal of Adult Intelligence Baltimore: Williams and Wilkins. 4th edition, 1958.

${ }^{19}$ Wechsler D. Wechsler Intelligence Scale for Children Revised Manual New York: Psychological Corporation, 1974.

${ }^{20}$ Nee LE, Caine ED, Polinsky RJ, Eldridge R, Ebert MH. Gilles de la Tourette syndrome: clinical and family study of 50 cases. Ann Neurol 1980;7:41-49.

${ }^{21}$ Cohen DJ, Shaywitz BA, Caparulo B, Young JG, Bowers MB. Chronic multiple tics of Gilles de la Tourette's disease. Arch Gen Psychiatry 1978;35:245-50.

${ }^{22}$ Wilder J, Silbermann J. Beitrage zum tic problem. Abhandlungen aus der Neurologie, Psychiatrie, Psychologie und ihren Grenzgebeiten Berlin: Karger S. 1927. 
${ }^{23}$ Bleeker HE. Gilles de la Tourette's syndrome with direct evidence of organicity. Psychiatr Clin N Am 1978;11:147-54.

${ }^{24}$ Fahn S. A case of post-traumatic tic syndrome. In: Friedhoff AJ, Chase TN, eds. Gilles de la Tourette syndrome. Adv Neurol Vol. 38. New York: Raven Press, 1982:349-50.

${ }^{25}$ Puist S-M, Walshe TM, Romero JA. Carbon monoxide poisoning with features of Gilles de la Tourette syndrome. Arch Neurol 1983;40:443-4.

${ }^{26}$ Sacks O. Acquired Tourettism in adult life. In: Friedhoff AJ, Chase TN, eds. Gilles de la Tourette syndrome Adv Neurol Vol. 35. New York: Raven Press, 1982:89-92.

${ }^{27}$ Klawans HL, Falk DK, Nausieda PA, Weiner WJ. Gilles de la Tourette syndrome after long term chlorpromazine therapy. Neurology (Minneap) 1978;28:1064-8.

${ }^{28}$ Richardson EP. Neuropathological studies of Tourette syndrome. In: Friedhoff AJ, Chase TN, eds. Gilles de la Tourette syndrome New York: Raven Press, 1982:83-8.

${ }^{29}$ Bergen D, Tanner CM, Wilson R. The electroencephalogram in Tourette syndrome. Ann Neurol 1981;11:382-5.

${ }^{30}$ Feild JR, Corbin KB, Goldstein NP, Klass DW. Gilles de la Tourette syndrome. Neurology (Minneap) 1966;16:453-562.

${ }^{31}$ Prechtl HFR, Stemmer ChJ. The choreiform syndrome in children. Develop Med Child Neurol 1962;4:119 27.

${ }^{32}$ Trimble MR, Perez MM, Pratt RTC. Some uses of pro- lactin in psychiatry. In: Adv Biol Psychiat Vol. 5. Basel: Karger, 1980:46-57.

${ }^{33}$ Caparulo BK, Cohen DJ, Rothman SL, et al. Computed tomographic brain scanning in children with developmental neuropsychiatric disorders. J Am Acad Child Psychiatry 1981;20:338-57.

${ }^{34}$ Caine ED, Polinsky RJ. Tardive dyskinesia in persons with Gilles de la Tourette disease. Arch Neurol 1981;38:471-2.

${ }^{35}$ Lundh H, Tunving K. An extrapyramidal choreiform syndrome caused by amphetamine addiction.J Neurol Neurosurg Psychiatry 1981;44:728-30.

${ }^{36}$ Osler W. In: On chorea and choreiform affections. Philadelphia: Blakiston, 1894.

${ }^{31}$ Corbett JA. The nature of tics and Gilles de la Tourette's syndrome. In: Abuzzahab F, Anderson F, eds. Gilles de la Tourette Syndrome International Registry. St. Paul: Mason Publishing Co, 1976.

${ }^{38}$ Thorne FC. Startle neurosis. Am J Psychiatry 1944;101:105-9.

${ }^{39}$ Simons RC. The resolution of the latah paradox. J Nerv Ment Dis 1980;168:195-206.

${ }^{40}$ Gastaut H, Villeneuve A. The Startle disease or hyperekplexia: Pathological surprise reaction. $J$ Neurol Sci 1967;5:523-42.

${ }^{41}$ Markand D, Garg BP, Weaver DO. Hyperekplexia (hereditary startle disease) electrophysiologic findings. Neurology (NY) 1982;32(2):A68.

${ }^{42}$ Nuwer MR. Coprolalia as an organic symptom. In: Friedhoff AJ, Chase TN, eds. Gilles de la Tourette syndrome New York: Raven Press, 1982:363-8. 